\title{
EXPERIMENTAL AND CALCULATED PHOTOPEAK EFFICIENCIES FOR A COAXIAL Ge(Li) DETECTOR*
}

\author{
D. E. RAESIDE and M. A. LUDINGTONं \\ Physics Department, The University of Michigan, Ann Arbor, Michigan 48104, U.S.A.
}

Received 29 December 1970

Experimental and calculated photopeak efficiencies have been obtained for a $32 \mathrm{~cm}^{3}$ true coaxial Ge(Li) detector at four distances: $2 \mathrm{~cm}, 5 \mathrm{~cm}, 10 \mathrm{~cm}$ and $20 \mathrm{~cm}$. A comparison of these results is presented.

During the past few years several papers discussing the experimental efficiency calibration of $\mathrm{Ge}(\mathrm{Li})$ detectors have appeared ${ }^{1-7}$ ). Recently a paper by Aubin et al. ${ }^{8}$ ) describing a Monte Carlo computer program to calculate the efficiency of planar and true coaxial $\mathrm{Ge}(\mathrm{Li})$ detectors has been published. The present investigation was undertaken to provide a comprehensive comparison between the calculated results obtained with this program and experimental results obtained with the pair-point method $^{1-4}$ ). Ten sources were used to

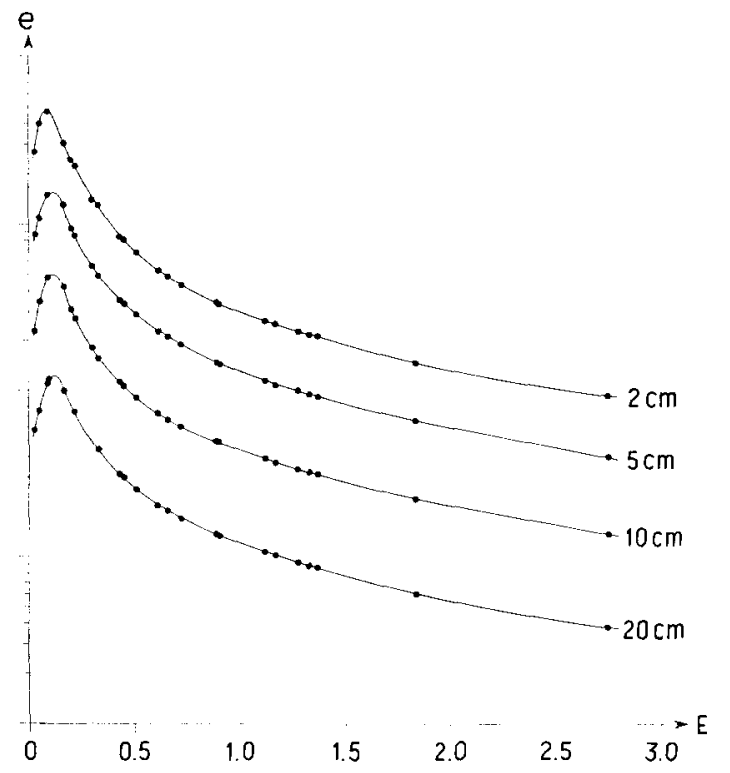

Fig. 1. The photopeak efficiency $(e)$ of a $32 \mathrm{~cm}^{3}$ true coaxial $\mathrm{Ge}(\mathrm{Li})$ detector (diameter $35.8 \mathrm{~mm}$; length $39.2 \mathrm{~mm}$; drift depth $11.8 \mathrm{~mm}$; diffusion depth $0.9 \mathrm{~mm}$ ) for a point source on the symmetry axis of the detector at distances $2,5,10$ and $20 \mathrm{~cm}$ from the face of the detector. The scale of the ordinate is logarithmic; the scale of the abscissa is linear and the units are $\mathrm{MeV}$. The absolute efficiencies at 2, 5, 10 and $20 \mathrm{~cm}$ are $2.15 \times 10^{-3}, 9.40 \times 10^{-4}, 3.17 \times 10^{-4}$, and $8.81 \times 10^{-5}$, respectively, for the $1333 \mathrm{keV}$ gamma ray of ${ }^{60} \mathrm{Co}$. Here we understand absolute efficiency to mean the probability of the emission of a photon into an appropriate solid angle and its subsequent detection as a photoelectric event.

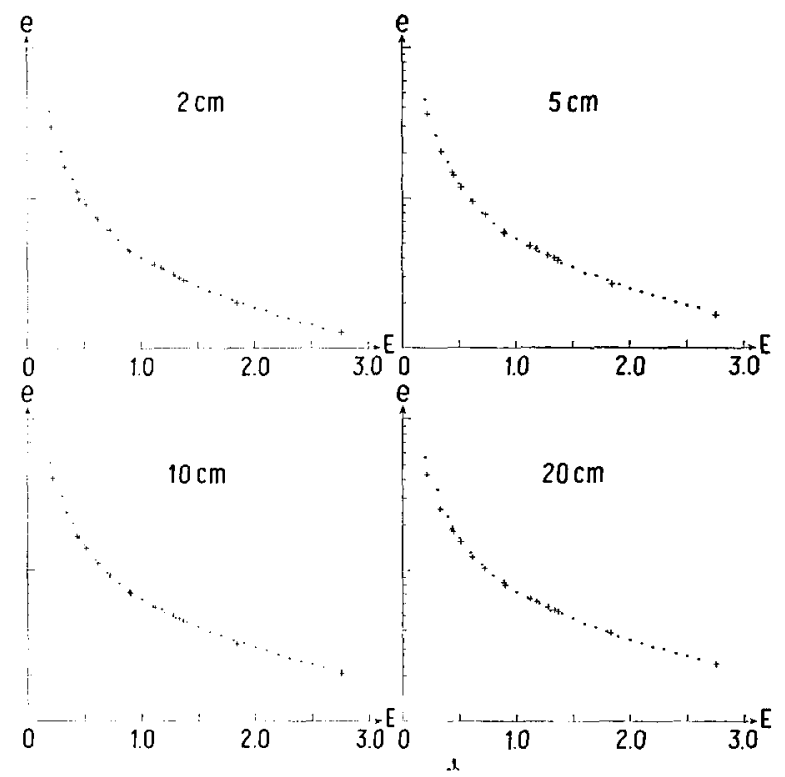

Fig. 2. A comparison of experimental and calculated photopeak efficiencies $(e)$ for a $32 \mathrm{~cm}^{3}$ true coaxial $\mathrm{Ge}(\mathrm{Li})$ detector. The experimental values were overlapped with the calculated values visually to obtain the best fit. The scale of the ordinate is logarithmic; the scale of the abscissa is linear and the units are $\mathrm{MeV}$. The dots represent calculated values and the crosses represent experimental values.

obtain the data for the experimental officiency curves of fig. 1: ${ }^{22} \mathrm{Na},{ }^{60} \mathrm{Co},{ }^{46} \mathrm{Sc},{ }^{108 \mathrm{~m}} \mathrm{Ag},{ }^{88} \mathrm{Y},{ }^{24} \mathrm{Na}$, ${ }^{180 \mathrm{~m}} \mathrm{Hf},{ }^{137} \mathrm{Cs},{ }^{139} \mathrm{Ce}$ and ${ }^{160} \mathrm{~Tb}$. The program of Aubin et al. ${ }^{8}$ ) was run on the PDP- 10 computer of the University of Michigan physics department. Several hours of running time were required to obtain the data for each source-to-detector distance. Photon cross sections used in the calculations were taken from the work of Storm and Israel $^{9}$ ); detector dimensions were

* This work was supported in part by the U. S. Atomic Energy Commission.

† Present address: Physics Department, Albion College, Albion, Michigan. 
taken from the specifications of the manufacturer (Ortec). A comparison between experimental and calculated values is shown in fig. 2. Because of the fact that the computer program can not reproduce the hump [produced by attenuation in the surroundings of the $\mathrm{Ge}(\mathrm{Li})$ crystal] at the low-energy end of each of the curves shown in fig. 1, the data of fig. 2 start at an energy well beyond this hump $(0.2 \mathrm{MeV})$. As fig. 2 shows, the agreement between experimental values and calculated values is excellent.

The authors wish to thank Prof. M. L. Wiedenbeck for his continuing interest in this work and Prof. J. W. Chapman for providing generous amounts of computer time.

\section{References}

1) J. M. Freeman and J. G. Jenkin, Nucl. Instr. and Meth. 43 (1966) 269.

3) W. R. Kane and M. A. Mariscotti, Nucl. Instr. and Meth. 56 (1967) 189.

3) D. P. Donnelly, H. W. Baer, J. J. Reidy and M. L. Wiedenbeck, Nucl. Instr. and Meth. 57 (1967) 219.

4) D. P. Donnelly and M. L. Wiedenbeck, Nucl. Instr. and Meth. 64 (1968) 26.

5) R. S. Mowatt, Nucl. Instr. and Meth. 70 (1969) 237.

i) V. W. Slivinsky and P. J. Ebert, Nucl. Instr. and Meth. 71 (1969) 346.

7) T. Paradellis and S. Hontzeas, Nucl. Instr. and Meth. 73 (1969) 210.

8) G. Aubin, J. Barrette, G. Lamoureux and S. Monaro, Nucl. Instr. and Meth. 76 (1969) 85.

9 E. Storm and H. I. Israel, Los Alamos Scientific Laboratory Report LA-3753 (1967). 